\begin{tabular}{|c|c|c|}
\hline $\begin{array}{l}\text { FATIH } \\
\text { SULTAAN } \\
\text { MEHMET } \\
\text { vakFF UNIVERSiTESi } \\
2010\end{array}$ & $\begin{array}{l}\text { FSM İlmî Araştırmalar Insan ve Toplum Bilimleri Dergisi } \\
\text { FSM Scholarly Studies Journal of Humanities and Social Sciences } \\
\text { Sayı/Number } 13 \text { Yıl/Year } 2019 \text { Bahar/Spring } \\
\text { (c) } 2019 \text { Fatih Sultan Mehmet Vakıf Üniversitesi }\end{array}$ & 口iring \\
\hline DOI: 10.16947/fsmia.582444 & http://dergipark.org.tr/fsmia & http://dergi.fsm.edu.tr \\
\hline Yayın Değerlendirme / Book Reviews & - Geliş Tarihi / Received: 01.05.2019 Kabul Tarihi / Accepted: 20.06.2019 - FS & FSMIAD, 2019; (13): 511-520 \\
\hline
\end{tabular}

\title{
Mustafa Imamović, Boşnakların Tarihi, çev. Hüseyin Gül, Cenita Özgüner,
}

İstanbul: Tarih Vakfı Yurt Yayınları, 2018, 9789753333542, 728 s. +dizin

Emine Tonta $\mathrm{Ak}^{*}$

Eser, yazarın Historija Bosnjaka adıyla 1997 yılında ilk kez yayınlanan kitabının 1998 tarihli ikinci baskısı esas alınarak, Mehmet Ö. Alkan'ın önsözü ve Hüseyin Gül-Cenita Özgüner'in çevirisiyle Türkçeye kazandırılmıştır. Kitabın Bosna tarihi literatürüne katkısı, özellikle 1992-95 Bosna Savaş1 ertesinde bir zorunluluk olarak, yeniden inşa sürecine giren Boşnaklık / Bosnalılık milli kimliği açısından yadsınamaz derecede önemlidir. Imamović kitabında Bosna tarihini, ilk defa bu denli bütünlükçü bir bakış açısıyla, ortaçağdaki kökenlerinden başlayarak 1990'lı yıllara kadar gelen süreçte tüm evrelerini kapsayacak şekilde ele almaktadir.

Kitap, giriş ve sonuç bölümleri ile birlikte on bölümden oluşmaktadır. Yazar, giriş bölümünde eseri kaleme almasının fikri ve tarihi nedenlerini kanıtlarıyla ortaya koyarak, aslında Bosnalıların uzun geçmişlerinin de kısa bir özetini yapmaktadır. Eser, batılı oryantalist bakışın, Boşnak yurduna ve kimliğine karş1, “Avrupa ve Şark'ın kıyısındaki puslu bir vilayetin egzotik dünyası” şeklinde resmettiği "Bosnalı Müslümanlar ve Bosna sanısını", şoven milliyetçi Balkan propagandasının ve ondan beslenerek artan Avrupa merkezli tarihsel tahribatın temellerini açığa çıkarmaktadır. Bu bağlamda eser, modernist teorinin, Bosna tarihini, Osmanlı tarihinin de bir parçası olarak, “Avrupa'nın en gelişmiş bölgeleri ile anlamsız karşılaştırmalar yaparak" onu hapsettiği analojik anlatının geri kalmışlık dayatmasına ve dolaylı olarak da batı-merkezli evrensel tarih kurgusuna güçlü bir eleştiri getirmektedir.

Dr. Öğr. Üyesi, Fatih Sultan Mehmet Vakıf Üniversitesi Edebiyat Fakültesi Tarih Bölümü, İstanbul/Türkiye, etak@fsm.edu.tr, orcid.org/0000-0001-8365-0540 
Birinci bölümde, ortaçağ döneminde Bosna tarihi, Ortaçağ Bosna Devleti’nin gelişim kronolojisi içerisinde devrin önemli siyasi meseleleri ile toplum ve ekonomisi, en önemlisi de Bosna Kilisesi'ni ele almaktadır. Bu bölüm, Boşnak milli kimlik kurgusunun derin köklerini ortaya çıkarması açısından eserin bilhassa en önemli kısımlarının başında gelmektedir. Yazar bu bölümde, Bosna'nın tarihsel ve ulusal kimliğinin temellerini itina ile döşemektedir. Bunu yaparken, zengin bir kuramsal ve tarihsel literatürden beslenen metin, ulusçuluk kuramına "dil, din ve coğrafya" eksenlerinde önemli açılımlar getirerek, Balkanlardaki farklı kimlik yapılarının da analizini yapmaktadır.

Eserin ikinci bölümünde esas olarak, Bosna tarihinin Osmanlı hakimiyeti altında geçirdiği dönem konu edilmektedir. Bölümün girişinde yazar, Osmanlı Devleti'nin beylikten geniş bir imparatorluğa dönüşmesinin ardında yatan askeri ve siyasi aklı, devletin kuruluş felsefesini, yönetimi altındaki çoklu unsurları idare etme becerisinin şifrelerini özenle ortaya çıkarmaktadır. Balkan ve Avrupa literatüründe ağırlıklı olarak empoze edilmekte olan, "erken dönem Osmanlıların ilkel göçebe insanlar olduklarına dair" düşünce kalıplarını eleştiren yazar, tersine "siyasal örgütlenmede üstün meziyetleri olan" Osmanlıların, "güçlü bir devlet inşa etmek için yeterli özgüce sahip olduklarını" vurgulamaktadır. Osmanlıların yönetimleri altındaki Hristiyan ve Musevi tebasına "huzurlu yaşam tesis etme becerisini" Osmanlı müesseselerine dayandırarak açıklamaktadır (s.111-114). Bu bölümde esas olarak, Bosna'nın fethi ve sonrasında Osmanlı Devleti'nin Bosna'da oluşturduğu düzenin sosyo-ekonomik ve askeri yapısını, tarımsal düzenin özelliklerine vurgu yapılarak izah edilmektedir. Osmanlı hakimiyeti altında bulunan gayrimüslim milletlerin kazanımlarına dikkat çekilirken, beylikten kozmopolit bir imparatorluğa giden sürecin temel dinamikleri açıklanmaktadır (s.116-117). Yazar, özellikle Sırpların Osmanlı yönetimi altında daha önceleri hiç olmadığı kadar dini örgütlenme hakkına sahip olduklarının altını çizerek, "Osmanlılara değin, bir tek manastırlarının bulunmadığı Bosna Hersek' in birçok bölgesinde yerleşme fırsatı bulduklarını”, sadece Bosna'da toplam "7 manastırla beraber sayısız kilise inşa ettiklerini" ifade etmektedir (s.115). XIX. yüzyılın başlarından itibaren Sırp isyan ve isyancılarının karakteristiği üzerine önemli bilgiler verilmektedir. Sözkonusu isyanların sadece Osmanlı yönetiminin egemenlik haklarını değil, "Bosnalı müslümanların fiziki varlığını da" tehdit ettiği açığa çıkarılmaktadır (s.414-415).

Bu bölümde ayrıca, Bosna'da İslamiyet'in kabulü süreci ve ardında yatan sosyo-kültürel ve iktisadi unsurlar ortaya çıkarılmaktadır. Bosna'da tesis edilen Osmanlı şehirlerinin özellikleri ve şehir yaşamına yer verilmekte, Osmanlı'nın batı sınırını oluşturan eyalette Avusturya ile yaşanan uzun savaşlara değinilmektedir. Bosna'da kurulan Osmanlı sınır teşkilatının Osmanlı'nın batıdaki sefer ve ku- 
şatmalarındaki rolü "Kandiye ve Viyana Savaşları ve Kuşatmaları" anlatılmaktadır. Aynı bölümde Doğu Sorunu çerçevesinde Dubica Savaşı ele alınmaktadır. Osmanlı Bosnası'nda XIX. yüzyıla damgasını vurmuş iki temel meseleden biri olan olan Hüseyin Kapetan Gradaščević İsyan1, eyaletin "otonomi mücadelesi" perspektifi üzerinden açıklanmaktadır. İsyanı "Bosna'nın otonomi mücadelesi" olarak nitelendirilirken, sosyal ve siyasal konumlarını tehdit altında hisseden ayan ve kapetanların devletin merkezileştirme siyasetine tepkisi olarak yorumlanmaktadır. Eserin bu bölümü, dikkatli okuyucu için, özellikle sınır boylarındaki eyaletlerde "sosyal tabakalaşmanın" kalınlaştırdığı güçlü imtiyaz kümelenmelerinin, uzunca bir dönem örtüşen yerel ve merkezi çıkarların ördüğü ittifak zincirinin, oluşma ve kopma sorunsalının anlaşılması açısından önemli tespitler sunmaktadır. Yüzyılın diğer önemli meselesi olan, eyalette Tanzimat reformlarının uygulanması ise tarımsal ilişkiler bağlamında ele alınmaktadır. İmamović, Bosna'da 1867 yılından itibaren vilayet nizamnamesinin uygulanmasına, reform sürecinin hayata geçirilmesi açısından özel bir önem atfetmektedir. Öyle ki, bunu "Anayasa Kanunu hüviyetinde bir düzenleme" olarak nitelendirirken (s.429), 1860'l1 y1llarda Bosna'da idari, siyasi, ekonomik ve kültürel alanlarda yaşanan Osmanlı yenileşme hareketine dikkat çekmektedir (s. 429-430).

Eserin üçüncü bölümü, Bosna-Hersek'in Avusturya Macaristan tarafından işgali (1875-1878) meselesine ayrılmış olup, işgal sürecinin Doğu Krizi ve Berlin Kongresi bağlamındaki gelişimi ortaya çıkarılmaktadır. Sırbistan, Karadağ'daki müslümanların ve Boşnakların durumları ve Bosna-Sancak ve İstanbul Konvansiyonu oluşumlarının açılanması ile de işgalin ardından oluşan diplomatik süreç ve toplumsal sonuçlar ele alınmaktadır. İmamović, kendi akademik uzmanlık alanlar1 arasında olan, yüzyılın son çeyreğinden itibaren, Bosna-Hersek' in, ilki "Büyük Doğu Krizi (1875-78)" olarak nitelendirilen Hersek İsyanı ve devamındaki Avusturya işgalinde, ikincisi 1908-1909 ilhak y1llarında ve üçüncüsü de 1914'te olmak üzere "dünya siyasetinin merkezine" nasıl itildiğini detaylarıyla açıklamaktadır. Avusturya işgalinin stratejik gerekçelerini detaylandırırken, 1850'lerden itibaren bu amaçla yapılan askeri ve diplomatik hazırlıklara dikkat çekmektedir. Bosna'nın işgalini, Avusturya açısından önemli bir siyasi ve ekonomik yayılma hedefi olmasının yanında, güney sınırlarında bir Slav devletinin kuruluşunun engellenmesi demek olduğuna vurgu ile, üçlü fayda ekseninde analiz etmektedir (s.431-433). 15 Ocak 1877 tarihli Budapeşte Konvansiyonu ile Avusturya'nın

1 "sosyal tabakalaşma" için bkz. Max Weber, Ekonomi ve Toplum, Yarın Yayınları, 2012. Ayr1ca bkz. Kemal Karpat, "Some historical and methodological Considerations Concerning Social Stratification in the Middle East", Commoners, Climbers and Notables, ed. C.A.O van Nieuwenhuijze. Leiden, E.J. Brill, 1977. 
işgal için uygun zaman ve yöntemi belirleme hakkı kazanmasını, Osmanlı-Rus Savaşı'nın sonucu olarak ortaya çıkan yeni güçler dengesinde Ayastefanos Anlaşması ve Berlin Konferansı'nı Bosna-Hersek'in işgaline giden kilometre taşları olarak ele alarak, sözkonusu sürecin diplomasi masasına yansımalarına işaret etmektedir (s.434-435). Bu bölümde ele alınan diğer bir mesele ise Berlin Konferansı'nın (35. madde ile) yarattığı siyasi sonuçlarının neden olduğu, bölge halklarını etkileyen demografik sonuçlar, yani göç olgusudur. Bu bağlamda Sırbistan ve Karadağ'daki Müslümanların ve Boşnakların durumu, Osmanlı topraklarına Müslüman halkın göçleri ile dağlardaki Ortodoksların da onlardan boşalan yerlere göçü ele alınmaktadır (s.437).

Dördüncü bölümde, Bosna'da Avusturya işgali sonrasında yaşanan siyasi değişim, dış etkiler ve Boşnak toplumunun iç dinamikleri açısından değerlendirilmektedir. 1878-1888 yılları arasında Türkiye'ye yaşanan göç hareketinin yanısıra, 1899 'da Dzabič liderliğindeki Boşnakların kültürel özerklik mücadelesi ele alınmaktadır (s.447-448). Burada Türkiye'ye göç sürecini dönemselliği, nedenleri ve Avusturya yönetiminin göç karşısındaki tutum ve icraatları açıklanmaktadır (s. 454461). İmamović, işgal sonrasında Bosna'daki müslüman nüfusun mutlak olarak artmasına rağmen, toplam nüfus içindeki azalan oranına dikkat çekmektedir. Ayrıca Avusturya makamlarının göç eden müslüman sayısını abartılı biçimde eksik göstererek örtmeye çalışmasına vurgu yapmaktadır (s.460). Böylelikle yazar, Avusturya işgal hükümetinin Türkiye'ye göçler karşısındaki tutum ve siyasetini deşifre ederek, eleştirmektedir (s.458-460). Diğer taraftan bu bölümde Bosna işgal yönetimlerinin karakterleri üzerinde de durulmaktadır. Avusturya işgal yönetimlerinin, General Filipovic'den Benjamin Kallay'a, Bosna'da uyguladıkları Avusturya politikasının değişen eğilimleri değerlendirilmektedir. General Filipović döneminde uygulanan "Hırvatlaştırma siyasetinin" başarısız ve talihsiz çabaları ortaya çıkarılırken, Filipović sonrası dönemde Benjamin Kallay idaresinin Bosna'da tatbik etmeye çalıştı̆̆ 1 "dinler-mezhepler arasında denge ve eşitlik" siyasetinin neden ve sonuçlarına dikkat çekilmektedir (s. 462-464). 1882 yılında yönetimi devralan Benjamin Kallay'ın, Sırp hareketinin "irredentist eğilimlerini”" tehdit unsuru olarak algıladığını ve buna son verilmesine yönelik önlemler aldığının altı çizilmektedir. Böylece, Bosna'da Sırp ekolünün dizginlenme çabaları ile birlikte, Kallay'ın “Bosnalılık” üzerine inşa etmeye çalıştığı geniş kapsamlı bir ulusal hareketin temellerini atma çabalarına dikkat çekilmektedir. ${ }^{2}$ Bu bölümde, 30 yıllık işgalin ardından Bosna'nın 1908'de Avus-

2 Bu noktada Avusturya-Sırbistan ilişkilerinin Bosna'nın işgalinden itibaren bölgesel-uluslararası dengeler ve iki ülkenin çakışan çıkarları nedeniyle gerginleşmesi, özellikle "güçlü, büyük Sırbistan" idealinin Avusturya açısından hayati bir tehdit olarak algınıyor oluşu gibi faktörlerin, Bosna Hersek işgal yönetiminin değişen siyasetine yansımaları daha etkin bir şekilde vurgulanabilirdi. 
turya tarafından ilhakı ile Osmanlı'dan koparılması ve ardından yaşanan göçler de ele alınmaktadır. İlhakın uluslararası diplomasi açısından ele alınması, onun doğu sorunu çerçevesinde anlaşılabilmesine olanak sunmaktadır. Diğer yandan, Jön Türk Devrimi'nin Bosna-Hersek'in ilhakını, Avusturya açısından, nasıl hızlandırdığı gerçeğine dikkat çekilmektedir (s.520-527). Bölümün son kısmında ise ilhak sonrası Bosna'da yaşananlar, yeni siyasal düzenin gelişimi, yeni anayasa, parlemento ve siyasal partilerin oluşum süreci ile Bosnalı Müslüman hareketinin durumu detaylı bir şekilde ele alınmaktadır (s.539-576).

Kitabın beşinci bölümünde, Bosna'nın I. Dünya Savaşı'nın fitilinin ateşlendiği yer olması itibarıyla yeniden dünya gündeminin merkezine çekilmesi ile yaşanan büyük kriz ve ertesinde yaşananlar detaylı olarak ele alınmaktadır. Savaş yıllarında yeniden gündeme gelen, Avusturya ve Macaristan arasında da sorun teşkil eden Bosna Hersek' in statü sorunu açıklanmaktadır (s. 577-585). Bölümün diğer kısmında ise, XIX. yüzyılda güney Slav halklarının ortak bir devlet kurma fikri olarak ortaya çıkan, XX. yüzyılın ilk on yılında Sırbistan'da gelişen, Balkan Savaşları sırasında siyasi bir önem elde eden "Yugoslavya fikri(leri)"nin gelişimi anlatılmaktadır (s.585-600).

Altıncı bölümde ise, genel olarak ilk Yugoslav Devleti döneminde (19181941) Bosna Hersek'in politik yapılanması konu edilmektedir. Yugoslav Hükümeti'nin yapılanma süreci ve bu yapı içerisindeki farklı siyasal eğilimler, Boşnakların yeni hükümet ve siyasi partiler içerisindeki temsili meseleleri ele alınmaktadır. Yeni kurulmakta olan Yugoslav Devleti'nde iktidarın merkezileştirilmesi eğilimi doğrultusunda, Bosna-Hersek Halk Hükümeti'nin isminin Yerel Hükümet olarak değiştirilmesi ve önemli bakanlıkların Belgrad'daki merkeze bağlanmasıyla yerel yönetimin etkisizleştirilmesi süreci anlatılmaktadır. Kral Naibi Aleksandar'ın yönetiminde oluşturulan yeni Yugoslav Devleti'nin (Sırp, Hırvat ve Sloven Krallığı) birinci hükümet döneminde, Boşnakların siyasi temsilinin zayıflığ 1 gözler önüne serilmektedir ${ }^{3}$ Yine aynı bölümde, Yugoslavya'da siyasal partilerin yapılanma süreci, özellikle Yugoslav Müslüman Partisi'nin oluşumu ve Boşnakların karşılaştı̆̆ı sorunlar açıklanmaktadır. İki Dünya Savaşı arası dönemde, Bosna Hersek’teki siyasi ilişkileri ağırlıklı olarak "karakterize eden siyasal-partisel dağınıklığa" dikkat çekilirken, bu durumun nedeni olarak da "ülkenin siyasi-ekonomik sorunlarına yönelik farklı görüşlerin, Bosna-Her-

3 Öyle ki, Bosna Hersek’te hükümete giren üç bakandan sadece birisi, yani hükümetteki tek Boşnak, Orman ve Tabi Kaynaklar Bakanı, Dr. Mehmet Spaho’dur. Yine Yugoslav Meclisi'nin bir organı olan Geçici Halk Temsilciliği’ne Bosna Hersek’ten katılan 42 vekilin arasında sadece 11 Boşnak vardır. (s.601-605). 
sek' in karmaşık etnik ve dini yapısının bir sonucu olarak ortaya çıktığı" iddiasına yer verilmektedir (s.609). Diğer bir önemli mesele olarak ise, 1910 yılına oranla 1921 'e gelindiğinde Bosna Hersek nüfusu içerisindeki Boşnak nüfusunun azalmış olması vurgulanmaktadır. Bu durumun nedenleri olarak da, "öncelikle savaş, Yugoslav Devleti'nin ilan edilmesi sonrasındaki ilk yıllarda Boşnak nüfusunun karşılaştığ1 zulüm ve sürgünler" gösterilmektedir (s.609). Yugoslav Devleti'nin kuruluş yıllarında "egemen olan ulusal ve devlet üniterizmi ideolojisi"nin dayattığı ama aslında gerçekçi olmayan "tek Yugoslav halkı" ve onu teşkil eden üç "soy": Sırp, Hırvat ve Sloven" yaklaşımını eleştiren yazar, Boşnakların bu suni ve dayatmacı siyasal kurgu içerisinde, farklı bir kültürel-dini grup olarak dahi temsil edilemediklerine dikkat çekmektedir (s. 610). Sözkonusu bölümde, ayrıca 1919-1921 yıllarında Bosna Hersek'te kurulan, farklı etnik ve sınıfsal çıkarlar1 temsil eden yeni siyasal partilerle ilgili bilgiler verilerek, siyasal mozaik betimlenmektedir. Bu farklı eğilimlerdeki partilerden, merkeziyetçi tarafta, "ulusal ideolojik temel üzerinde", kurulan Demokrat Parti ile Boşnakların yerel siyasi partilerinin birleşmesi ile kurulan, tek Boşnak siyasi partisi Yugoslav Müslüman Partisi (JMO) üzerinde hassasiyetle durulmaktadır (s.610-612).

Bu bölümün diğer konuları, "kurucu meclis ve Vidovdan Anayasası" başlığı altında, Yugoslav Devleti'nin anayasasını yapmak üzere oluşturulan kurucu meclisin yapısı, çalışma alanları ile devletin anayasal meseleleridir. Meclis seçimlerine tüm Krallık içinden toplam 22 siyasi partinin katılmış olmasını yazar, "yüksek orandaki politikleşmeye işaret ettiğì" şeklinde değerlendirmektedir. Bosna Hersek'teki seçimden birinci parti olarak çıkan Yugoslav Müslüman Partisi’nin başarısını ise, "bütün sosyal sınıflara mensup Boşnakların, siyasi temsilcisi olmayı başardığı" şeklinde yorumlamaktadır (s.613). Yugoslavya Krallığı'nın devlet yapısında kuruluşundan beri varolan diktatörlük eğilimlerinin tamamen ve ağır bir biçimde gerçeğe dönüştüğü 1929 senesinde, 6 Ocak kararlarıyla diktatörlük ilan edilmesi bu bölümün en önemli meselelerinden birisini oluşturmaktadır. Diktatörlük ilanının, dayandırıldığı gerekçelerin yanısıra, Sırp, Hırvat ve Boşnak muhalafetinin, bu keskin durum karşısında sessiz kalışı da üzerinde durulan konular arasındadır (s. 623-626). Ülkenin rejiminin yanısıra idari yapısını da neredeyse tamamen değiştiren sözkonusu kararların alındığı 1929 senesi icraatlarının ana amacını yazar, "saf ulusal ünitarizmin canlandırılması" ve radikal bir merkezileştirme yoluyla "devlet-ulus birliğinin" sağlanması olarak özetlemektedir. Böylelikle sözde federal devlet düzenlemesi kisvesi altında "tam merkezileşmenin" gerçekleştirilmesi süreci ifşa edilmektedir (s.624-638). Ne var ki, Altı Ocak Diktatörlüğü olarak anılan yeni rejimin yasal temelleri, kralın 3 Eylül 1931 tarihinde halka "sunduğu" "Yugoslavya Krallığı'nın İkinci Anayasası" ile onaylanarak, oluşturulmuştur (s.631). Yeni ana- 
yasaya göre, sınırlı haklar, çift meclisli (Millet Meclisi ve Senato) bir parlamentonun kuruluşu ile de gizlenmiştir. Kralın elindeki iktidar araçlarından birisi haline gelen Senato'nun üyelerinin yarısı da yine kral tarafından atanmıştır. Böylelikle rejim, kişisel özgürlükler ve medeni haklar bakımından da sınırlı bir parlementer monarşi görünümlü diktatörlüğe evrilmiştir.

Ne var ki, 1935 senesi bir değişime işaret etmektedir. 1931 seçiminden edindikleri deneyimler nedeniyle muhalefet, 1935 y1lındaki meclis seçimlerini birleşerek kazanmış, böylelikle yeni ve çok unsurlu bir koalisyon hükümeti kurulmuştur. Böylece diktatörlük dönemi ve onun "kaba şiddetle anılan birleşik Yugoslavya siyaset ve ideolojisi” de resmen sona ermiştir (s.639). Bu bölüm 1939-1941 döneminde, yani Yugoslavya'nın savaşa girmesine kadar, Hırvat, Sırp ve Boşnak halklarının siyasi mücadelesini, bu dönemde kurulan Cvetković-Macek Hükümeti (Hırvat-Sırp koalisyonu)'nin faaliyetlerini ve Boşnak ulusuna yaklaşımını konu almaktadır. Sözkonusu koalisyon hükümetinin en önemli icraatlarını, Hırvatistan Banlığı'nın kurulması, Sırp Ülkeleri Banlı̆̆ çatısı altında Drava ve Slovenya banlıklarının teşkiline yönelik federalist planlamalar oluşturmuştur. Ağustos 1939 tarihli yeni koalisyon hükümeti anlaşması ile Bosna-Hersek' in toplamda 13 şehri Hırvatistan Banlığı kapsamına girmiştir. Böylece "Bosna-Hersek'in geniş ölçüde bölünmesi, paylaşılması ve tarihi dokusunun tamamıyla paramparça edilmesi” tamamlanmıştır (s.643). Diğer taraftan, bu yeni düzenleme ile Altı Ocak Diktatörlüğü'nün mirası olan "halkın ve devletin birliği” zorlaması ve yapay "Yugoslav halkı" fikriyatı da terkedilmiştir. Ne var ki, devletin bu yeniden yapılanma süreci özellikle Sırp siyasetçilerin Boşnakların ulusal varlığını inkar eden yaklaşımları nedeniyle sakat bir zeminde ilerlemiştir. 1939 yılında JMO'nun Hırvat, Sırp ve Sloven banlıklarının yanında dördüncü olarak Bosna-Hersek'in tarihi sınırlarında bir Bosna Banlığı oluşturulması talepleri karşılanmamıştır.

Tüm bu engellemeler, Boşnakların tepkisine neden olmuş, Boşnak siyasi önderliğinin Bosna-Hersek'in özerklik mücadelesi için, "ülkenin yeniden yapılandırılması sürecinde bağımsız ve eşit bir birim olarak" Boşnak varlığının kabul edilmesi yönündeki talepleri için birleşmişlerdir. Büyük protestoların ardından, 30.12.1939 tarihinde Boşnak sivil ve siyasi kurumlarının katılımıyla yapılan toplantıda, "Bosna-Hersek'in özerkliği için, ülke çapında yerel komitelerin kurulması talebiyle Bosna Hersek Özerklik Hareketi” tesis edilmiştir. Boşnakların Yugoslav Halkları Birliği’nin eşit bir unsuru olmak için hak talepleri, özellikle Sırp siyasetinin karşı çıkması sebebiyle hayata geçirilememiş ve tüm bu siyasi süreçler 1941 Nisan'ında başlayan savaş ve Yugoslav Krallı̆̆ı'nın çöküşü ile kesintiye uğramıştır (s.644-645). Bölümde ayrıca savaşa kadar geçen dönemde 
Bosna'nın sosyo-ekonomik durumu ele alınmakta olup, iki savaş arası dönemde, Avusturya dönemine nazaran ekonominin gelişmediği, yerinde saydığı da vurgulanmaktadır (s.651-652).

Kitabın yedinci bölümünde, 1941 Mart'ında Yugoslavya'nın Üçlü İttifaka katılması ve ardından yaşanan, İngiliz istihbaratının desteğiyle gerçekleşen askeri bir darbe ile hükümetin reşit olmayan Kral II. Petar ve General Simović yönetimine geçmesi ile ülkede meydana gelen iç karışıklıklar üzerinde durulmaktadır. Almanya ve İtalya'nın darbe hükümetine güven duymaması neticesinde 06.04.1941 tarihinde müttefikleri Macaristan ve Bulgaristan ile birlikte (savaş ilanı dahi yapılmaksızın) Yugoslavya'ya saldırmaları ile savaşın başlaması ele alınmaktadır. Savaş başladığında kral, hükümet ve yüksek komuta kademesi kısa süre içinde ülkeyi terk etmiş, sadece 12 gün süren savaş sonunda Alman ordusu, Yugoslav ordusunun koşulsuz teslimini talep ederek ülkeyi tamamen işgal etmiştir. Böylelikle sınır bölgeleri Almanya, İtalya, Macaristan ve Bulgaristan arasında bölüştürülmüş, sınır çizgisinin güneyi İtalya'nın, kuzeyi ise Almanya'nın etki ve işgal bölgesi haline gelmiştir. Diğer yandan Ustaşa (Hırvat) birliklerinin komutanı Slavko Kvaternik, 10.04.1941 tarihinde Zagreb'de Alman himayesi altında Bağımsız Hırvatistan Devleti'nin kuruluşunu ilan ederek, yayınladığı deklarasyonla Bosna Hersek'i de yeni kurulan devlete dahil etmiştir. Böylelikle İtalya ve Almanya'nın anlaşması neticesinde, Bosna Hersek, Bağımsız Hırvat Devleti'ne bırakılmıştır. Her ne kadar Bosna Hersek'in sivil siyasi yönetimi Hırvat Devleti'ne bırakılmış ise de ülkenin yeraltı ve yer üstü kaynakları ile yollarının kontrolü Almanya'nın kontrolü altına girmiştir (s.653-655).

Bölümde detaylı olarak işgal sonrası Bosna Hersek'in paylaşım süreci ile birlikte Hırvat Devleti altında Boşnaklara uygulanan "Hırvatlaştırma siyaseti", "Aryan ırkına ait olduklarına dair bir Ustaşa kanunu" ile "tek taraflı olarak Hırvat ilan edilmeleri”" gibi, tarihi ve ulusal kimliklerinden mahrum edilmelerine yönelik çabalar ele alınmaktadır. Boşnak ulusuna yönelik sözkonusu siyaseti yazar, "özünde Boşnaklara karşı işlenen bir tür soykırım” olarak değerlendirmektedir (s.656-657). Hırvat Devleti'nin ve işgal yönetiminin uygulamalarının karşısında Boşnakların takındığı muhalif tavırların yanısıra, 1941-1943 yıllarında üç dalga halinde Boşnaklar üzerinde gerçekleştirilen Sırp-Çetnik soykırımı ile onbinlerce Boşnağın hayatına malolan kayıplar vurgulanmaktadır. Sözkonusu uygulamalar karşısında Boşnakların mücadelesi ile kurulan Boşnak Halk Kurtuluş Hareketi'nin siyasal mücadelesi de bölümün en önemli konularındandır. Bosna Hersek'in yeni kurulan demokratik ve federal Yugoslavya'nın içinde ayrı ve eşit bir federal birim olarak kurulması, özgürlük ve eşitlik temelinde yaşaması yönünde 1943- 
1946 dönemindeki siyasal mücadeleler ile bölüm nihayet bulmaktadır. İşgalden kurtarılmış Saraybosna'da Nisan 1945'de Bosna Hersek Halk Hükümeti'nin kurulması ve Aralık 1946'da Bosna Hersek Halk Cumhuriyeti'nin ilk anayasasının kabulü ile Bosna Hersek'in devlet oluşum süreci tamamlanmaktadır (s.670).

Kitabın sekizinci ve son bölümünde 1945-1990 yılları arasında Boşnakların ulusal kimliklerinin tanınma mücadelesi başta olmak üzere, savaştan aldıkları tahribat, yeni devletin uluslararası konumu, meclisler ile Tito-Stalin çatışmasının sonuçları, 1950 yılında çıkan Cazin İsyanı ve anılan dönemde Boşnakların siyasi ve kültürel durumu gibi son devrin çoklu meseleleri üzerinde durulmaktadır. Burada savaş sonrası Yugoslavya'nın yeniden kurulmasıyla faaliyete geçen Boşnak siyasi ve kültürel organlarından bahsedilmektedir. 1945 senesinde bir tür Boşnak siyasi temsil organı olarak, Saraybosna merkezli Bosna Hersek Müslümanlarının Merkez Komitesi ile yine aynı yılın sonbaharında ortak kültür ve eğitim derneği olarak PREPOROD'un kuruluşu anlatılmaktadır. Boşnak halkının 1941 sonrası verdiği mücadele neticesinde "Halk Kurtuluş Savaşı'nda" elde ettikleri haklar, önce 1947 yılında Müslümanların Merkez Komitesi'nin kapatılması ve 1949'da ise PREPOROD'un faaliyetlerine son verilmesi ile fillen ortadan kaldırılmaktadır. Böylelikle Boşnak kültürel özerkliğinin oluşturulmasına dönük araçlar tamamen terkedilmiştir. Eserde bunun nedenleri üzerinde detaylı bilgi verilmemektir. Ancak devletin yeniden yapılandırıldığı bu dönemin meclislerinde Boşnakların ayrı bir ulus olarak yer alamadığ 1 anlaşılmaktadır (s.679-683). Stalin'in 1953 'te ölümünden sonraki dönemde, 1955 yılından itibaren, Sovyet-Yugoslav ilişkilerinin normalleştiği ifade edilmektedir.

Son olarak XX. yüzyılının ikinci yarısında Boşnakların kültürel gelişimleri, eğitim, dini kurumlar, edebiyat ve basın alanındaki gelişmeler ele alınmaktadır. Yazar, 1960'ların sonunda ve 1970'lerin başında siyasi sistemdeki artan değişim talepleri neticesinde Boşnakların ulus olarak tanınmalarının gerçekleşmesini ve bunun 1974 anayasasına yansımasını ele almaktadır. Ancak, "Büyük Sırbistan'ın Yugoslavya'da yeniden kurulması" fikri Tito'nun ölümünden sonra yeniden hortlatılmış, dağılmanın yolunu açmıştır. Slovenya ve Hırvatistan'ın bağımsızliklarının ilanından sonra Bosna Hersek de 29.02.1992 tarihli referandumla bağımsızlığını ilan etmiş̧tir. Eser, 1992 yılında Bosna'ya karşı başlatılan "Büyük Sırbistan hedefli saldırılar" ve Bosnalı müslümanların uğradığı soykırım ile sona ermektedir. Ancak kitap büyük ölçüde savaş şartlarında kaleme alındığından, savaşın detayları ve sonucu anlatıda yer almamaktadır.

Kitap, kurgusal metodu itibarıla "kısa tarih" izlenimi yaratmakla birlikte, yazarın da belirttiği üzere yola bu niyetle çıkılmış olmasına rağmen zamanla de- 
ğişmiş ve ilaveler yapılmıştır. Eserin kapsamı ve kurgusu, sözkonusu formatın dışına çıkmış olsa da doğrudan dipnotlandırma sistemi tercih edilmemiş, kaynakçaya tarihsel dönemler bazında kitabın sonunda yer verilmiştir. Bu yöntemle eserin yazımında faydalanılan kaynakların bir arada ve açıklamalı olarak okura sunulması faydalı görünse de, böyle geniş kapsamlı bir eserde, kaynakların doğrudan dipnot sistemiyle verilmemiş olması akademik bilginin isabetli kullanımı ve aktarımı açısından sakıncalar taşıyabilir.

Kitabın zengin kaynakçası, ağırlıklı olarak Boşnak, Yugoslav ve batılı tarihçilerin eser ve incelemelerinden oluşturmaktadır. Diğer taraftan, özellikle Osmanlı dönemine dair bölümlerde, kitabın yazıldığı tarih itibarıyla sayıları az olmakla birlikte, Türk tarihçilerin eserlerinden yeterince faydalanılmamış olması dikkat çekicidir. Örneğin Ahmet Cevat Eren'in 1965 yılında yayınlanan Mahmud II. Zamanında Bosna-Hersek, başlıklı eseri ${ }^{4}$, imparatorluğun XIX. yüzyıl merkezileştirme siyasetinin Bosna Eyaleti'ne etkilerini ortaya koymasına rağmen kaynakçada yer almamıştır. Aynı şekilde Fikret Adanır, Kemal Karpat gibi Osmanlı Balkan tarihçiliğinin önemli isimlerinin bazılarının eserlerine de rastlanmamaktadır. ${ }^{5}$

Sonuç olarak eser, tarihyazıcılığı açısından değerlendirildiğinde, Bosna tarihini, son sürümü XIX. yüzyılda ortaya çıkan batı-merkezli dünya tarihyazımı içindeki "güneydoğu Avrupa" (Southeastern / Southeast Europe) ${ }^{6}$ kalıbına hapsedilmiş, kültürel öznellikleri gözardı eden yaklaşımlardan kurtararak, onun Bosnalıların ulusal tarihi olarak yeniden kaleme alınma girişimi olarak okunabilir. Sırp ve Hırvat tarihyazımının şoven ve yanlı yargıları ile komünist dönem balkan tarihyazımının Osmanlı Bosnası ve Boşnaklarla ilgili yarattığı evrensel bellek tahribatının XX. yüzyılın en karanlık insanlık dramının zihinsel altyapısının oluşumuna da yol verdiği düşünüldüğünde, eserin önemi daha da artmaktadır. Bu bağlamda İmamović eseriyle, şoven milliyetçi ve hamasi söyleme prim vermeksizin inşa ettiği Bosnalıların uzak geçmişlerinden bugüne uzanan tarihlerini, zengin kaynaklarla ve nesnel bir dönemselleştirme ile balkan tarihyazımı içerisindeki hakikat çizgisine çekmekte, önemli bir eksikliği doldurmaktadır.

4 Ahmet Cevat Eren, Mahmud II. Zamaninda Bosna-Hersek, Nurgök Matbaas1, 1965.

5 2000'li yılların başından itibaren ise Türkiye'de ve dünyada Bosna Tarihi üzerine araştırmalarda görece bir artış yaşanmıştır. Hatice Oruç, Aydın Babuna, Zafer Gölen, Mehmet Emin Yardımcı, Fatma Sel Turhan, Emine Tonta Ak gibi Türkiyeli tarihçilerin Osmanlı Bosnası'nı konu alan araştırmaları dikkat çekicidir.

6 Genellikle Balkanlar yerine tercih edilen "güneydoğu Avrupa" adlandırması, sözkonusu tarihyazımı formatının Osmanlı Balkanları için tercih ettiği terminolojinin ürünüdür. Bu nedenle, en azından Osmanlı hakimiyetini kapsayan devir için kullanımının kasıtlı bir analoji olduğunu vurgulamak isterim. 